Publicação organizada pelo Programa de

Mestrado Profissional Stricto Sensu em

Engenharia Civil da Universidade São Judas

Volume 02 - Edição 01

Janeiro - Dezembro de 2019

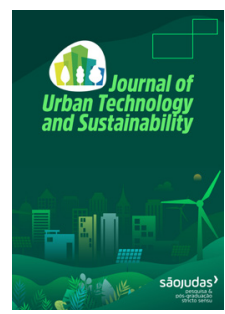

\title{
Análise do plano de gestão integrada de resíduos sólidos de Imperatriz (MA) para o gerenciamento de resíduos sólidos urbanos
}

Márcio A.S. Silvaa, Marcela B. Moraes ${ }^{a,}$, , José L.G. Silva ${ }^{a}$

${ }^{a}$ Programa de Pós-graduação em Gestão e Desenvolvimento Regional, Universidade de Taubaté - UNITAU.

\section{Informações}

Recebido 14 Outubro 2019

Manuscrito revisado recebido 09 Dezembro 2019

Aceito 12 Dezembro 2019

Palavras-chave

Planejamento

Desenvolvimento regional

Gerenciamento de resíduos

sólidos

Resíduos sólidos urbanos

Imperatriz

\section{Resumo}

Este artigo tem como objetivo descrever como ocorre o descarte dos resíduos sólidos e analisar a política pública de tratamento de resíduos sólidos na cidade de Imperatriz, estado do Maranhão. Tratase de um estudo documental, com abordagem descritiva e delineamento qualitativo. Cabe mencionar que a cidade de Imperatriz se encontra entre aquelas que já implantaram o Plano Municipal de Gerenciamento de Resíduos Sólidos Urbanos (RSU). O processo de coleta promove a cidade status de referência para outras cidades, por ter despertado um olhar acerca das questões ambientais e a ligação com o processo industrial. Assim, o estudo evidencia que os RSU refletem ainda insatisfação entre a população e a administração pública. Pode-se entender que no que concerne a política pública de RSU, o município de Imperatriz tem cooperado para o gerenciamento. Ao desenvolver o plano, além da contribuição com o meio ambiente em que está inserido, destaca-se os incentivos federais para a continuação do desenvolvimento das atividades relacionadas.

\section{Analysis of the Imperatriz solid waste integrated waste management plan for urban solid waste management}

\section{Article info}

Received 14 October 2019

Received in revised form 09 December 2019

Accepted 12 December 2019

\section{Keywords}

Planning

Regional development

Solid waste management

Urban solid waste

Imperatriz

\section{Abstract}

This paper aims to define how the disposal of solid waste occurs and to analyze the public policy for the treatment of solid waste in the city of Imperatriz, state of Maranhão. It is a documentary study, with a descriptive approach and qualitative design. It is worth mentioning that the city of Imperatriz is among those already implemented in the Municipal Plan for the Management of Urban Solid Waste (USW). The collection process promotes a state of reference for other cities, for having aroused a look at environmental issues and the connection with the industrial process. Therefore, the study shows that USW still reflects dissatisfaction between the population and the public administration. It can be understood that this is not a public USW policy, the municipality of Imperatriz has been cooperating for management. In developing the plan, in addition to the contribution to the environment in which it is inserted, the federal incentives for the further development of related activities are highlighted.

\section{Análisis del plan de gestión integral de residuos sólidos de Imperatriz (MA) para la gestión de residuos sólidos urbanos}

\section{Información}

Recibido 14 Octubre 2019

Manuscrito revisado recibido 09 Diciembre 2019

Aceptado 12 Diciembre 2019

\section{Palabras clave}

Planificación

Desarrollo regional

Manejo de residuos sólidos

Residuos sólidos urbanos

Imperatriz

\section{Resumen}

Este artículo tiene como objetivo describir cómo se eliminan los residuos sólidos y analizar las políticas públicas para el tratamiento de residuos sólidos en la ciudad de Imperatriz, estado de Maranhão. Es un estudio documental, con enfoque descriptivo y diseño cualitativo. Cabe mencionar que la ciudad de Imperatriz se encuentra entre las que ya han implementado el Plan Municipal de Gestión de Residuos Sólidos Urbanos (RSU). El proceso de recolección promueve el estatus de ciudad de referencia para otras ciudades, por haber suscitado una mirada a la problemática ambiental y la conexión con el proceso industrial. Así, el estudio muestra que los RSU aún reflejan el descontento entre la población y la administración pública. Se puede entender que en lo que concierne a la política pública de RSU, el municipio de Imperatriz ha colaborado para la gestión. En el desarrollo del plan, además del aporte al entorno en el que se inserta, se destacan los incentivos federales para el mayor desarrollo de las actividades relacionadas.

\footnotetext{
* Autor correspondente em: Programa de Pós-graduação em Gestão e Desenvolvimento Regional, Universidade de Taubaté - UNITAU. 


\section{Introdução}

A Política Nacional de Resíduos Sólidos (PNRS), aprovada em 2010 (PNRS, 2010) pelo estado brasileiro frente às responsabilidades com os Resíduos Sólidos Urbanos (RSU), busca implementar intervenções que fossem capazes de minimizar ou fechar todos os lugares que eram utilizados como lixões. Todas as cidades do país deveriam apresentar meios alternativos, tendo como exemplo: coleta seletiva, logística reversa, compostagem dos resíduos e a participação dos cidadãos (FERRI et al., 2015).

Nessa crescente, o assunto tem gerado enfoque de mídias em todos os meios de veiculação mundial. Esse ponto se deve ao consumo desenfreado frente aos padrões de compra que prejudicam a forma sob a qual se apresenta os recursos naturais (FERREIRA DA CUNHA et al., 2015).

O capital, presente socialmente e distribuído entre as classes, possibilitou o poder de compra e consequentemente a elevação dos RSU, que relacionados ao descarte irregular, contribui veementemente para que as problemáticas ambientais continuem sendo destaque por depreciar aspectos essenciais a continuidade da vida humana (GODECKE et al., 2015).

Da mesma forma, o progresso relacionado ao aumento dos municípios brasileiros não foi proposto ou planejado, atitude que desencadeou consequências relacionadas ao descarte de entulhos a céu aberto. Por consequências, exige-se intervenções que tornem congruente o edificar das cidades e a expansão do lixo urbano (FERRI et al., 2015).

Ao descartar os resíduos em locais inaptos, acontece o escoamento do chorume, que coopera para que o solo terrestre seja prejudicado, além de permitir a reprodução de animais que são capazes de prejudicar à saúde humana através da veiculação de doenças (FERRI et al., 2015).

Como resultado do crescimento desgovernado de inúmeras localidades, aumentou-se também as dificuldades sociais, econômicas, culturais e ambientais, o que exige diversos atos em busca de soluções alternativas, assim o planejamento e o gerenciamento por meio dos governos públicos são essenciais nesse processo.

No momento em que cresce a quantidade de RSU, eleva-se o descarte irregular que contribui para que o meio ambiente continue sendo agredido, o que minimiza o equilíbrio no ecossistema mundial. Cabe mencionar que dentre os objetivos para um pleno desenvolvimento em todo o planeta, a agenda das Nações Unidas busca o consumo e produção responsáveis, fazendo-se necessário a seguridade entre o que é produzido e o consumo do homem em uma linha de equilíbrio (NAÇÕES UNIDAS BRASIL, 2015).

Nesse contexto, as cidades passaram a seguir os preceitos estabelecidos na PNRS (2010) implementando o recolhimento seletivo através de licenças, por outro lado diligenciou incentivos as associações de catadores de materiais recicláveis, para que as problemáticas relacionadas ao recolhimento fossem atenuadas.

O aumento das áreas urbanas e rurais favorece a inexistência de um planejamento adequado, além de ocupações de áreas improprias para a moradia humana. Ademais, a crescente populacional gera impactos diretos no processo econômico, na educação e no processo de infraestrutura, pois quanto mais o território se expande mais necessários tornam-se os meios para administrar o que se é consumido pelos indivíduos. Essas ações frente ao poder de compra tornam-se necessárias para que não ocorra mais descarte irregular.

Os questionamentos que norteiam o estudo referem-se a: "De que forma a política pública de gestão deresíduos sólidos do município de Imperatriz (MA) tem contribuído para o gerenciamento dos resíduos sólidos urbanos (RSU)? Quais são as ações que o município tem realizado? Quanto em recursos públicos é destinado ao gerenciamento desses resíduos? As diretrizes implantadas têm-se tornado suficientes para que exista uma destinação adequada?

Faz-se necessário examinar na referida política pública, quais as contribuições dos munícipes, para qual locais o que é coletado está sendo destinado, de que forma acontece a acomodação, 
quais os incentivos financeiros empregados pela prefeitura e se existe atenção para que não haja comprometimento da população que vive nos lixões. Nesse contexto, o trabalho está pautado no seguinte objetivo: descrever como ocorre o descarte dos resíduos sólidos e analisar a política pública de tratamento de resíduos sólidos na cidade de Imperatriz (MA).

\section{Referencial teórico}

A revolução industrial no século XVIII desencadeou melhorias na economia mundial. Somado a isso, o crescimento das populações, os novos aspectos da economia de grandes nações, o desenvolvimento de tecnologias e produção em maiores linhas tornaram-se fatores predisponentes para que 0 aumento da quantidade de RSU.

Dados das Nações Unidas, publicados ne revista do Senado Federal Brasileiro em (2014), demostram que entre 20\% a 30\% das receitas municipais são destinadas a administração de RSU e suas variáveis, como acomodação, triagem, transporte e destinação final adequada e menos agressiva aos ecossistemas.

O que é consumido pelas pessoas por muitas vezes segue para destinação irregular, o que acarreta mazelas a natureza, principalmente dentro das cidades, o que propicia uma cascata de problemas sociais, econômico, ambientais e de saúde. A não efetivação de um gerenciamento contamina o solo, as margens de rios, promove erosões ao solo, prejudica a flora e polui o meio ambiente.

Uma pesquisa da Associação Brasileira de Empresas de Limpeza Pública e Resíduos Especiais (ABRELPE) confirma que no Brasil muitas toneladas são destinadas dia a dia irregularmente, um pouco mais da metade das cidades da união, precisamente 3.923 já adotaram modelos para filtrar o que é coletado.

Ainda sobre o destino dos RSU, eles possuem uma destinação final que onera os sistemas financeiros de estados, cidades e do Distrito Federal. Atualmente o que é produzido pode ser destinado e utilizado em diferentes fins a saber: lixão, aterro controlado, aterro sanitário, incineração, compostagem, biogás.

Diante das questões mencionadas, sugere-se que as condutas sejam repensadas em vista a um futuro mais consciente e equilibrado. No país, a PNRS tornou-se a cerne de direcionamento para que condutas fossem tomadas, cabendo enfatizar que nela foi determinado o encerramento dos lixões a céu aberto, reafirmando também todos os impactos por eles causados.

O que retorna da coleta seletiva advém das parcerias firmadas em todas as unidades federativas, entre as prefeituras e os catadores de materiais recicláveis. Essa associação garante que bons resultados se devam ao trabalho que ambos desenvolvem linha tênue, já que a inexistência ou falha no processo de coleta mantem-se como um dos impasses na gestão das cidades (BRANDÃO; SILVA, 2011).

Se comparado o ano de 2016 com 2017, observase um crescimento na coleta das regiões brasileiras, sendo que o Sudeste se consolida como destaque, com porcentagens superiores as nacionais. Por meio da ABRELPE (2017) foi possível confirmar que nem todas as cidades brasileiras possuem uma coleta seletiva que contemple as suas áreas urbanas, e mais da metade do que é coletado é enviado aos aterros sanitários, evidenciando um processo ainda defeituoso.

Ademais, em outras o destino principal concentra-se nos lixões e aterros controlados que segundo a PNRS são inadequados, e agravando a situação, mais de 80 mil toneladas de resíduos são depositadas diariamente, potencializando a poluição ambiental e repercutindo em aspectos maléficos à saúde.

Os municípios concentrados na região Nordeste geraram, em 2017, a quantidade de 55.492 toneladas/ dia de RSU, embora mais de $70 \%$ tenham sido recolhidas espera-se aumentar esse potencial. Dos resíduos coletados na região, 64\% foram coletadas diariamente, ou destinados para lixões e aterros controlados.

O custo mensal por pessoal pago pelas cidades concentradas nessa região acima é superior a RS 
8,00 por pessoa na coleta de RSU e demais serviços de limpeza urbana. Ressalta-se que mais de R\$ 6 bilhões foram movimentados no que concerne ao processo de limpeza urbana destes municípios, um crescimento de mais de $6 \%$ se comparados aos índices de 2016.

\subsection{Quase uma década da Política Nacional de Resíduos Sólidos}

Anualmente, estados e municípios são recordados das obrigatoriedades dispostas na PNRS (2010), o seu maior dispositivo é a adoção de novas condutas de estados, municípios e união para com o que é produzido após o consumo.

A referida lei, conceitua coleta seletiva como sendo a separação prévia de acordo com a estrutura e composição dos produtos. Acerca do gerenciamento do RSU, as atitudes tomadas direta ou indiretamente, dos RSU, e propor destino que contemplem um fim seguro e menos agressivo ao solo e que esteja de acordo com a PNRS e os planos municipais.

Dentre os dispositivos mencionados na PNRS, os que possuem maiores ênfases são: coleta seletiva, logística reversa, compostagem dos resíduos e a participação dos cidadãos, entre outros que juntos poderão fornecer resultados positivos na linha apresentada nesse estudo.

Entre as metas que se busca obter, estão: eliminar e recuperar as áreas que foram utilizadas para serem os lixões, incluir socialmente e proporcionar autonomia de catadores de materiais reutilizáveis e recicláveis.

Os grandes centros urbanos, enfrentam complexidades relacionadas ao crescimento dos números de habitantes e proporcionalmente ao lixo que produzem, fazendo imprescindível prover soluções para coordenar esses insumos.

Esse excessivo número de lixo urbano, desencadeiam situações socioambientais e sanitárias de grande repercussão. Isso exige dos administradores públicos das urbanizações, reduzir o que é produzido, propor circunstâncias predeterminadas ao que foi gerado e fornecer intervenção aos rejeitos de forma adequada.

O pensamento ecológico dos seres humanos, é indispensável para que novos hábitos, padrões de consumo e adoção de novas condutas reduzam a geração em demasia do lixo. Assim, os processos pedagógicos em educação ambiental implantado nas escolas são alternativas para responsabilização comunitária, ou seja, o crescimento e desenvolvimentos das crianças e jovens com olhar crítico para questões ambientais.

Provavelmente os impasses referem-se à continuidade empresarial na criação, elaboração e fabricação de produtos e como controlar os efeitos sobre o meio ambiente. Analogamente, a PNRS aplicou em seu texto o critério de que todos os envolvidos estariam responsáveis pelo decurso do que seria produzido, comercializado e excluso (BATISTA, 2018).

As administrações federais e estaduais, passaram a ser incumbidas de constituir os campos de ações, providenciar os recursos relacionados a infraestrutura para que todo o material coletado fosse retirado das cidades e desprezado em locais próprios, da mesma forma seriam ajuizados regular, supervisionar e acompanhar a aplicabilidades da lei $n^{0} 12.305 / 2010$.

Do mesmo modo, as prefeituras municipais, passariam a ser a implementadoras do plano que gerenciasse de forma ambientada os RSU. Ao mesmo tempo, os setores de economia particular, aplicariam a logística reversa, recuperando o que fora coletado e destinando-o adequadamente. Por fim, aos cidadãos, o ofício de separar, acomodar separando por característica e constituição, o lixo e o que estaria apto a reciclagem, desprezando correta e ambientalmente.

Por consequência das dificuldades que se apresentaram no percurso, em quase um período de dez anos, avanços foram obtidos, conquistas enaltecidas e benefícios recebidos das operações desenvolvidas. Como resultado, o Observatório dos Lixões (2019) aponta que dos 5570 municípios existentes no país, somente 2064 possuem aterro sanitário, 2402 ainda destinam os insumos em lixões ou aterros controlados, e 2251 apresentam 
coleta seletiva. Destaca-se que somente, 1744 detêm plano municipal.

Portanto, os lixões a céu aberto continuam sendo uma realidade, e menos da metade das cidades, implantaram os dispostos que prega a PNRS, fato que sugere falhas na fiscalização.

Destarte, o crescimento dos Resíduos sólidos urbanos após aprovação da política, continua sofrendo destinação irregular, impropria e afetando o processo de urbanização. Faz-se indispensável, gerenciar, aplicar o que dispões os meios, fiscalizar as ações desenvolvidas, incentivar o trabalho dos catadores, solidificar mais associações, desenvolver o incentivo fiscal para novas recicladoras, buscar parcerias por Organizações Não Governamentais (ONGs) entre outros (KUHN; BOTELHO; DE ALMEIDA ALVES, 2018).

\subsection{Gerenciamento de resíduos sólidos urbanos em Imperatriz}

O presente estudo refere-se ao município de Imperatriz, estado do maranhão (Figura 1). Este está localizado na região Nordeste do Brasil, na divisa com o estado de Tocantins às margens do Rio Tocantins, sendo a segunda maior cidade do estado. As principais vias de acesso ao município são a MA-122, BR-010 e a TO-409. Com mais de 100 povoados e $1.367,9 \mathrm{~km}^{2}$ de área total, correspondendo em torno de 0,46\% do território do Estado do Maranhão (IBGE, 2010).

Os números expressos pelo Instituto Brasileiro de Geografia e Estatística (IBGE, 2010) afirmam que o município possuía uma população de 247.505 habitantes em 2010. Em relação as estimativas (2017), este número está próximo a 254.569 habitantes. O território expressa uma densidade demográfica de aproximadamente $181 \mathrm{hab} / \mathrm{km}^{2}$.

É notório o depósito irregular de resíduos nas principais ruas da cidade. A adversidade maior encontra-se relacionada ao lixão, que fica localizado há mais de 10 quilômetros do centro, nele são descartados distintos sedimentos. Esse cenário foi proibido pelo Art. 15 parágrafo V da lei PNRS (2010) autorizando aos municípios que desenvolvessem meios para que houvesse correta gestão e

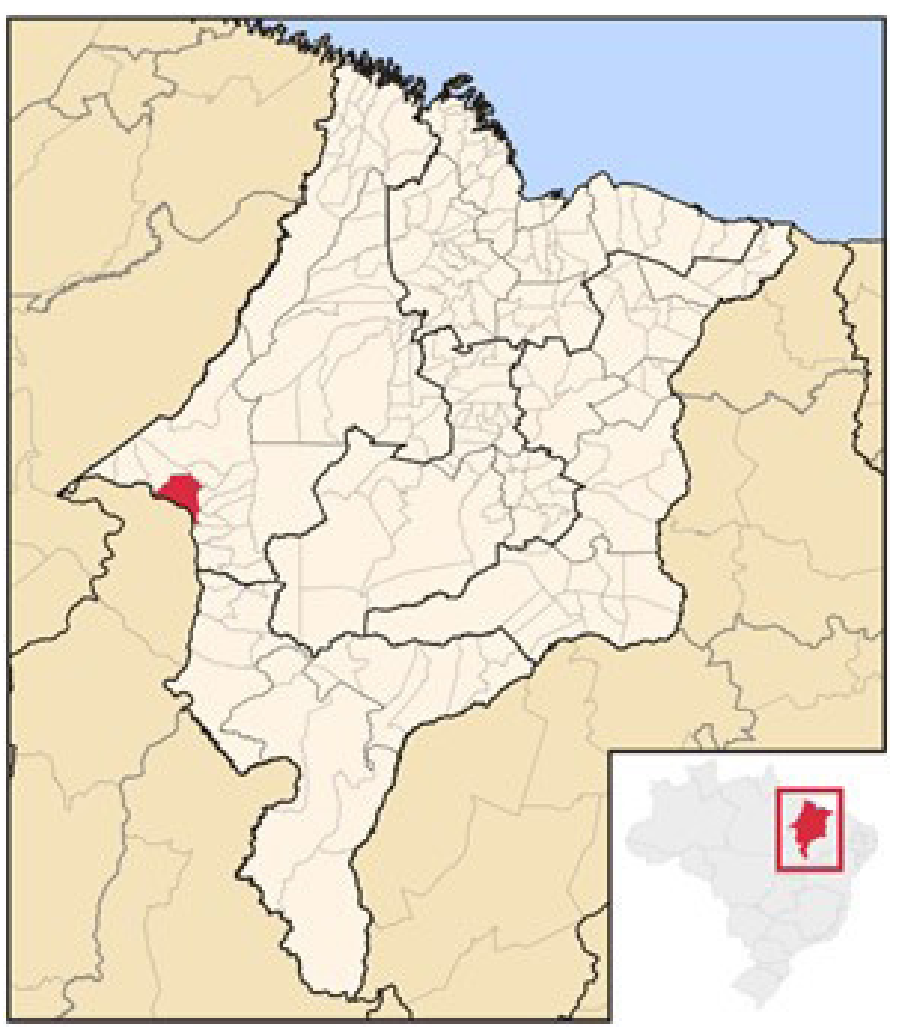

Fig. 1. Munícipio de Imperatriz, estado do Maranhão (Atlas de Desenvolvimento do Brasil 2010).

gerenciamento e intervenções direcionadas ao crescimento sustentável.

O Plano Diretor de Imperatriz (Lei Complementar $N^{0} 001$ /2018) estabelece que Plano de Gestão Integrada dos Resíduos Sólidos; compõe a política territorial da área urbana a área rural. Ademais o plano descreve as principais ações estratégicas dispostas no Art. 79 da lei mencionada quadro 01 abaixo (CÂMARA MUNICIPAL DE VEREADORES, 2018):

Sob perspectiva e olhar as estratégias listadas nesse quadro, a cidade de Imperatriz propõe que a parceria entre o público e o privado, a associação de catadores de materiais recicláveis e o cidadão municipal sejam corresponsáveis no gerenciamento que será destinado ao lixo.

A responsabilidade compartilhada é tratada de forma expressiva na lei federal de Resíduos Sólidos, para que todos envolvidos sejam articuladores e visem minimizar os comprometimentos, pois cada envolvido descrito (fabricante, distribuidor, comerciante, consumidor) possuem atribuições especificas. 


\section{Metodologia da pesquisa}

Trata-se de um estudo documental, com abordagem descritiva e delineamento qualitativo. Esse tipo de estudo permite utilizar-se de documentos sejam atuais ou retrospectivos, em busca de um entendimento histórico para que seja possível uma análise e interpretação das condicionalidades envolvidas (KITCHENHAM et al., 2013). O levantamento bibliográfico foi realizado em bibliotecas convencionais, a saber: Google Scholar, site da Prefeitura Municipal de Imperatriz, Política Nacional de Resíduos Sólidos, Plano Diretor de Imperatriz e Confederação Nacional de Municípios e Resíduos Especiais, bem como os sites para a captação de publicações que contemplem o tema em questão.

Buscou-se estabelecer critérios, assim incluiu-se: Artigos que tenham um dos seguintes Descritores: Desenvolvimento Regional, Resíduos Sólidos; Política Nacional de Resíduo Sólidos. Artigos publicados na íntegra disponíveis nas bases de dados selecionadas, no período de 2010 a 2019; Publicações do Ministério do Meio Ambiente que abordem o tema. Foram excluídos os artigos cujas metodologias não possibilitam obter informações que atinjam o objetivo desse estudo.

O período de coleta de dados refere-se ao mês de agosto de 2019. Em um primeiro momento, foi realizado o levantamento da literatura disponível nas bases de dados propostas e no site da Prefeitura de Imperatriz através do Plano Municipal de Gestão Integrada de Resíduos Sólidos - Imperatriz. Posteriormente realizou-se uma leitura exploratória e analítica dos resumos das respectivas literaturas, para assim selecionar a amostra.

\section{Resultados e discussão}

Os impactos ambientais no lixão na cidade de Imperatriz são visíveis, podendo-se destacar: catadores de materiais recicláveis residindo no próprio local, sendo expostas ao forte odor, presença de vários animais e insetos, entre outros transmissores de doenças. Além disso, a poluição atmosférica através da emissão tóxica proveniente da queima dos resíduos causa danos à saúde dos
Tabela 1. Apresentação do perfil nacional relativo ao painel de controle dos planos municipais para gerenciamento dos Resíduos Sólidos Urbanos (Adaptado de Observatório dos lixões, 2019).

\begin{tabular}{cc}
\hline Situação & Municípios (quantidade) \\
\hline Não Informado & 888 \\
Em elaboração & 1919 \\
Finalizado & 1744 \\
Não Iniciado & 1019 \\
TOTAL & 5570 \\
\hline
\end{tabular}

catadores, os quais são expostos a uma série de doenças (SANTOS; RIGOTTO, 2008).

Os números apresentados pelo Observatório dos lixões da Confederação Nacional dos Município (CNM) infere que em relação aos planos municipais, existem aspectos importantes sobre as responsabilidades das cidades com a aplicação das leis e diretrizes (CONFEDERAÇÃO NACIONAL DOS MUNICÍPIOS, 2019). Além disto, o Observatório engloba dados, notícias e informes acerca das cidades, e como estão conduzindo os processos pertinentes a gestão dos RSU e as obrigações da PNRS.

Como já mencionado, a PNRS tem por decisão central o encerramento dos lixões em todo o estado brasileiro até meados de 2014, e que todo - lixo que fosse incapaz de ser reutilizado seja encaminhado para os aterros sanitários adequados (AGÊNCIA BRASIL, 2016).

Diante de tal aspecto, a Confederação Nacional dos Municípios (2019) apresentou uma sequência de dificuldades enfrentadas para que a implantação da PNRS seja eficiente, resolutiva e abrangente, assim foram listados: priorização da mesma nas políticas de governo, pouco investimento, ausência de leis que fomente outros interessados a participarem da aplicabilidade, além da pouca participação de indivíduos sociais por subjugarem que é responsabilidade do poder público, entre outras. A Tabela 1 apresenta o perfil nacional relativo ao painel de controle dos planos municipais para gerenciamento dos Resíduos Sólidos Urbanos.

Acerca desta Tabela 1, cabe mencionar que a cidade de Imperatriz se encontra entre aquelas que já implantaram o Plano municipal de 
gerenciamento de Resíduos Sólidos Urbanos. Isso foi implementado em maio de 2018, com a premissa de que a evolução desenfreada de RSU, somados a ausência da coleta, tratamento e disposição adequada deles fortalecesse o processo de agressão ao meio ambiente.

Acrescenta-se ainda, que o processo de responsabilidade écomuma outrossetores, camadas sociais e aos cidadãos. Desde o início da coleta da matéria-prima para fabricação, complemento ou desenvolvimento de um novo produto ao descarte pós uso, inúmeros são aqueles que estão interligados mesmos que desconhecidamente. Esses a partir da PNRS passaram a ser responsáveis por reduzir, reciclar e reutilizar o que for próprio para reinserção na cadeia de consumo, bem como na de produção empresarial.

Nesse aspecto, foram desenvolvidas na cidade ações para que as partes fossem conhecedoras e passassem a desenvolver atos que contribuíssem com o processo. Assim, educação nas escolas, reunião com a associação de catadores, visitas técnicas ao lixão municipal e com os que trabalham de forma autônoma na coleta de materiais recicláveis foram empregadas. Ademais, com os moradores da área urbana e rural dos municípios, todos que de uma forma direta ou indireta usufruam do serviço de tratamento, coleta e disposição final de resíduos sólidos.

Cabe destacar inicialmente, que antes da elaboração do Plano Municipal, foi criado um grupo que englobava o poder público local através da gestão municipal (Prefeito, vice-prefeito e a Secretária Municipal de Meio Ambiente e Recursos Hídricos - SEMMARH), e um comitê diretor local. Foi realizada a contratação por licitação pública de uma empresa para realizar a consultoria, com uma equipe técnica de 11 colaboradores.

Sobre a caracterização dos RSU de Imperatriz foram listados: Metal (nobres e não-nobres); Isopor; Papel, Papelão e Tetrapak; Plástico; Vidro; Orgânico; Rejeitos e outros. Porém, apesar da implantação da coleta seletiva municipal e do trabalho desenvolvido pelos catadores da associação, muito dos resíduos ainda não são reciclados e despejados em vias públicas.
$\mathrm{Na}$ Associação de Catadores de Materiais Recicláveis de Imperatriz - ASCAMARI o que é recolhido sofre um processo de classificação, separação e prensa. Após esse processo, os catadores comercializam para os locais que realizam a compra, como as recicladoras, e mesmo com todo o trabalho desenvolvido, de escuta, apoio, incentivo e reconhecimento, muitas lacunas existem, e fazem parte desse contexto, sugerindo que as ações não podem encerrar-se precocemente. É de grande importância valorizar tais colaboradores porque contribuem veementemente para que os resultados continuem sendo obtidos.

Nessa esteira, o processo de construção apesar de atual, vem beneficiando mais de 200 famílias que vivem em situação de vulnerabilidade social e têm na coleta de resíduos rendimento para prover as condições de moradia, alimentação e demais necessidades familiares.

No que diz respeito às características associadas ao gerenciamento das finanças relacionadas ao RSU da cidade, os dados são imprecisos, e passivos de alteração e a seguridade não são claros. Contudo, ao analisar o portal da transparência nos itens no qual é citado no plano municipal os contratos 051/2017 e 052/2017, depreende-se os informes a seguir.

Em relação ao contrato 051/2017, foi aberto um processo de licitação para que fosse contratada uma empresa, e que esta tivesse por especialidade, prestar ações que preservassem, realizasse a limpeza urbana, proporcionasse segurança além do transporte. Cabe mencionar, que os contratados da mesma seria também sua responsabilidade, porém deveriam estar em consonância a serviços necessário da cidade e pré-estabelecidos pela secretaria de infraestrutura, esse referido contrato possui um valor acima de RS 3 milhões de reais (PORTAL DA TRANSPARÊNCIA, 2017).

Já em alusão ao contrato 052/2017, com um valor também acima de $\$ 3$ milhões de reais, que tem como objetivo desta licitação, a realização de um contrato que desse por prioridade a instalação de uma organização empresarial voltada precisamente na locação de transportes, principalmente caminhões, e dispusessem de motoristas, para 
complementar o trabalho da secretaria citada acima, e em conformidade ao município (PORTAL DA TRANSPARÊNCIA, 2017).

Ainda sobre o Portal da Transparência (2018) da cidade, o processo de coleta de dados proporcionou encontrar o contrato $\mathrm{N}^{\mathrm{O}}$ 001/2018 - SEMMARH. Este contrato, com valor de R\$ 79.000, 00, proporcionou por meio do seu objeto a contratação de uma empresa para que fosse desenvolvido uma análise técnica de disposição final dos RSU com linha ambientalmente viável para a cidade.

Por sua vez, o contrato $N^{0}$ 003/2017 - SEMMARH buscou a contratação de uma empresa que também criasse um conjunto de ações em prol dos resíduos urbanos, de forma sustentável e condizentes as características políticas, econômicas, ambientais, culturais e sociais e que priorizasse a inclusão dos catadores sob a importância de desenvolvimento sustentável. O valor da contratação foi de RS 244.000 (PORTAL DA TRANSPARÊNCIA, 2017).

Assim, acerca dos gastos orçamentários da cidade, como destacado anteriormente, pode-se inferir um valor acima de R\$ 7. 506.217,52 aplicados em transporte, pessoal, empresa etc. Embora o atraso na aplicabilidade do plano municipal, muitos valores e ações foram investidos em um curto espaço de tempo.

O que é selecionado pelos associados da ASCAMARI, é comercializado às recicladoras, que segundo o plano concentram-se em um total de sete. Atuam como intermediárias dessa compra, adquirindo os resíduos por valor baixo e vendem dentro da linha de preços correspondente no mercado. Assim, compõe o quadro de recicladoras as seguintes iniciativas: Recicladora São Lucas, Recicladora RIPEL, Recicladora RESUL, Recicladora REMASUL, Recicladora RECIMAR, Recicladora São Salvador, Recicladora Santa Cecília

O processo de coleta promove a cidade ao status de referência para outras cidades, por ter despertado um olhar acerca das questões ambientais e a ligação com o processo industrial. Após o recolhimento dos materiais, os catadores desenvolvem seus trabalhos selecionando 0 necessário, separando o que foi desprezado pelas instituições empresariais, organizações e pessoas. Já nos Pontos de Entrega Voluntária, PEVs, são recolhidos os materiais que poderão ser reciclados. Os encargos e responsabilidades são desenvolvidos em colaboração, e juntos visam um objetivo comum (SECRETARIA DO MEIO AMBIENTE, 2019).

A coleta iniciou-se por distritos específicos, como as áreas dos bairros: Maranhão Novo, Três Poderes, Juçara, Avenida Dorgival Pinheiro de Sousa, Getúlio Vargas e no Calçadão, essas recebem em dias e horários específicos divulgados pela prefeitura a coleta em sistema de rotas (PREFEITURA MUNICIPAL DE IMPERATRIZ, 2019).

A expansão das atividades já atingiu a área rural. É proibido o descarte do RSU em regiões de solo e água produtivas para que não ocorra contaminação das fontes. Busca-se a educação ambiental em prol da conservação e manutenção da vida (SECRETARIA DO MEIO AMBIENTE, 2019).

A administração do que é produzido nas cidades tornou-se um problema a partir do instante que o acúmulo passou a afetar aspectos relacionados ao desenvolvimento sustentável. Por isso, gerenciar de forma adequada beneficia os cidadãos e os gestores públicos, o que estiver apto a reciclagem é reinserido na cadeia de produção, uma continuidade positiva que após tratados, as vantagens financeiras relacionadas ao processo, seja utilizando-se do que foi reciclado, seja negociando, reduz os impactos e proporciona trabalho e renda a inúmeros cidadãos (CARVALHO; ABDALLAH, 2012).

Prevenir, reduzir, reutilizar, reciclar, tratar os RSU e dispô-los adequadamente, tornam-se providências ambientalmente apropriada e oportunas do que é coletado através dos serviços de limpeza das cidades (DIAS, 2012).

Existe uma disparidade sobre esse assunto. Por isso, que as políticas públicas devem ser formuladas para contemplar as diferentes secretarias de uma cidade e juntas promovam o ensino ambiental, a adoção de novos padrões pelos agentes sociais, melhor uso da tecnologia para que eticamente os insumos tenham destinação conveniente (DIAS, 2012). 


\section{Considerações finais}

O estudo evidencia que os RSU refletem ainda a insatisfação entre a população e a administração pública, haja vista as inúmeras cidades do Brasil não dispõem de plano de resíduos ou um destino adequado final para o que é recolhido. A PNRS desencadeou grandes desafios para os prefeitos, governadores e a república federativa, relaciona-se ao gerenciamento de resíduos, com independência do tamanho, localização e economia do munícipio.

Pode-se entender no que concerne a política pública de RSU município de Imperatriz tem cooperado para o gerenciamento dos resíduos sólidos urbanos. Apesar de contemporânea, os impactos já são consideráveis, e resultados já são visíveis em uma esfera nacional como apontou uma pesquisa, que a cidade se encontra entre as principais em status brasileiro.

As ações de educação e conscientização da população foram adotadas em escolas, sociedades, empresas, entidades públicas e privadas, produzindo um alcance de grandes massas em prol da participação no processo de filtragem, separação, destinação e posterior reintrodução na cadeia de produção. Logo, conscientizar os indivíduos acerca da responsabilidade compartilhada é uma das diretrizes impregnadas na Política Nacional de Resíduos Sólidos, já que o decurso dos insumos passa por essas diferentes populações, setores e economias.

Nessa linha de pensamento, os municípios continuam a desenvolver parcerias com a Associação de Catadores de Materiais Recicláveis, com os Ponto de Entrega Voluntária de Resíduos, com os horários da rota da coleta seletiva comtemplando os bairros das cidades, em todos os dias da semana, em horários diurnos e noturnos. O grande destaque agora é ao enfoque relacionado a coleta na área rural, somados ao reflorestamento das nascentes de rios e lagos, e da orientação correta de descarte das embalagens de agrotóxico.

Em relação aos recursos públicos destinados ao gerenciamento desses resíduos, evidencia um cronograma financeiro acima do esperado em relação ao tempo de implementação do plano, além do mais beneficia as famílias que trabalham com o processo de reciclagem, as recicladoras no câmbio de produtos e as empresas compradoras.

Ao desenvolver o plano, o local além de contribuir com o meio ambiente em que está inserido, continuará a ganhar incentivos federais para que continue desenvolvendo suas atividades, ampliando a cobertura e concretizando dados que relevem o quão é importante para uma cidade o pensamento ecológico.

Debater, ter visão crítica e analisar a situação social da cidade em busca de vantagens e melhorias fazem da organização territorial um destaque porque implementa, otimiza e desenvolve meios para que a limpeza urbana, os catadores, as recicladoras e a população coparticipem da coleta e destinação dos RSU, recebendo melhorias em características relacionadas a qualidade de vida, ao saneamento e a sociedade geral.

Como resultado denota-se que as a diretrizes implantadas têm-se tornado suficientes para que exista uma destinação adequada, mas que muito está por vir pelas, as ações realizadas, as parcerias desenvolvias e os resultados estão se tornando notáveis, tanto a nível local, quanto estadual e federal.

Por fim, conclui-se que a partir da análise desenvolvida, a cidade em estudo, cresceu em um curto espaço de tempo, embora tenha tido uma lacuna administrativa na implementação de dispositivos capazes de contribuir e melhorar o gerenciamento dos RSU. Destaca-se que os procedimentos são contínuos, sujeitos a erros e acertos.

\section{Referências bibliográficas}

ALMEIDA JR, R. A.; AMARAL, S. P. Lixo urbano, um velho problema atual. In: XII Simpósio de Engenharia de Produção. 2006.

BARROS, L. Prefeitura divulga rotas da Coleta Seletiva: Cidadão pode se informar sobre o ponto mais próximo da sua casa, caso seu bairro não integre o cronograma de coleta seletiva domiciliar.

Prefeitura Municipal de Imperatriz, Imperatriz, 
1 jul. 2019. Disponível em: imperatriz.ma.gov.br/ noticias/coleta-seletiva/prefeitura-divulga-rotasda-coleta-seletiva.html. Acesso em: 3 set. 2019.

BATISTA, B. C. Análise de Efetividade dos Instrumentos Econômicos da Política Nacional de Resíduos Sólidos (PNRS). 97f. 2018. Dissertação (Mestrado em Engenharia e Desenvolvimento Sustentável). Universidade Federal do Espírito Santo, Vitória, 2018.

BRANDÃO, A. O.; SILVA, G. N. Impactos econômicos da implantação de aterros sanitários individuais nos municípios brasileiros. Holos, v. 3, p. 84-96, 2011.

BRASIL. Lei $\mathbf{n}^{\circ}$ 12.305, de 02 de agosto de $\mathbf{2 0 1 0}$ regulamentada pelo decreto $n^{\circ} 7.404$ de 23 de dezembro de 2010. Institui a Política Nacional de Resíduos Sólidos [PNRS]. Disponível em http://www. planalto.gov.br/ccivil_03/_ato2007-2010/2010/lei/ 112305.htm. Acesso em 20 jul. 2019.

BRASIL. Portal da Transparência. Prefeitura Municipal de Imperatriz. Contratos do Município: 00687 - Contrato $\mathbf{N}^{0} 051$ - SINFRA. Imperatriz, 7 dez. 2017. Disponível em: http://imperatriz.ma.gov.br/ contratos/processo.php?licitacao $=0 \&$ dispensa $=0$. Acesso em: 10 set. 2019.

BRASIL. Portal da Transparência. Prefeitura Municipal de Imperatriz. Contratos do Município: 00677 Contrato $\mathbf{N}^{\circ}$ 052/2017 - SINFRA. Imperatriz, 1 dez. 2017. Disponível em: http://imperatriz.ma.gov.br/ contratos/processo.php?licitacao $=0 \&$ dispensa $=0$. Acesso em: 10 set. 2019.

BRASIL. Portal da Transparência. Prefeitura Municipal de Imperatriz. Contratos do Município:

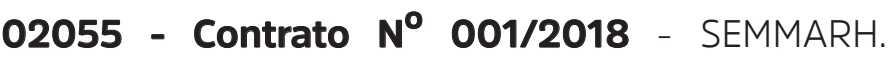
Imperatriz, 9 nov. 2018. Disponível em: http:// imperatriz.ma.gov.br/contratos/processo. php?licitacao=0\&dispensa=0. Acesso em: 10 set. 2019.

BRASIL. Portal da Transparência. Prefeitura Municipal de Imperatriz. Contratos do Município:

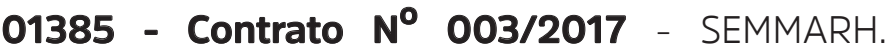

Imperatriz, 9 nov. 2018. Disponível em: http:// imperatriz.ma.gov.br/contratos/processo. php?licitacao=0\&dispensa=0. Acesso em: 10 set. 2019.

CÂMARA MUNICIPAL DE VEREADORES (Imperatriz). Prefeitura Municipal de Imperatriz. Lei complementar $\mathrm{N}^{0} 001 / 2018$ de 9 abr. 2018. Institui o Plano Diretor de Imperatriz e dá outras providências. Disponível em: http:// wWw.camaraimperatriz.ma.gov.br/images/ leis/2003ab96c9b0db01cddbe010093ee208.pdf. Acesso em: 3 set. 2019.

CARVAlHO, A. C.; ABDALLAH, P. R. Análise da gestão de resíduos sólidos no Terminal Porto Novo do Porto do Rio Grande, Brasil. Revista de Gestão Costeira Integrada, v. 12, n. 3, p. 389-398, 2012.

COSTA, L. Coleta Seletiva chega à zona rural de Imperatriz: moradores recebem orientações sobre coleta domiciliar e destinação correta de embalagens de agrotóxicos. Prefeitura Municipal de Imperatriz, Imperatriz, 16 abr. 2019. Disponível em: https://www.imperatriz.ma.gov.br/noticias/ coleta-seletiva/coleta-seletiva-chega-zona-ruralde-imperatriz.html. Acesso em: 27 ago. 2019.

COSTA, L. Imperatriz é referência em coleta seletiva no Maranhão: Cidade de Grajaú estuda modelo implantado na segunda maior cidade do Estado. Prefeitura Municipal de Imperatriz, Imperatriz, Imperatriz, 15 fev. 2019. Disponível em: https:// www.imperatriz.ma.gov.br/noticias/coleta-seletiva/ imperatriz-se-torna-referencia-da-coleta-seletivano-maranhao.html. Acesso em: 2 set. 2019.

DIAS, S. G. O desafio da gestão de resíduos sólidos urbanos. GV Executivo, v. 11, n. 1, p. 16-20, 2012.

FERREIRA DA CUNHA, N.; LUIZ BOZELLI, R.; FRANCO LEAL, G. Análise da aplicabilidade da lei 12305/2010 na gestão dos resíduos sólidos urbanos no município de Rio das Ostras, RJ-Brasil. Ambiental Mente Sustentable: Revista Científica Galego-lusófona de Educación Ambiental, v. 20, p. 1653-1668, 2015. 
FERRI, G. L.; CHAVES, G. L. D.; RIBEIRO, G. M. Análise e localização de centros de armazenamento e triagem de resíduos sólidos urbanos para a rede de logística reversa: um estudo de caso no município de São Mateus, ES. Production, v. 25, n. 1, p. 27-42, 2015.

GODECKE, M. V.; WALERKO, V. S. Gestão de resíduos sólidos urbanos: Estudo do caso da reciclagem em Pelotas, RS. Revista Gestão \& Sustentabilidade Ambiental, v. 4, n. 1, p. 104-128, 2015.

KITCHENHAM, B.; BRERETON, P. Uma revisão sistemática da pesquisa de processos de revisão sistemática em engenharia de software. Tecnologia da informação e software, v. 55, n. 12, p. 20492075, 2013.

KUHN, N.; BOTELHO, L. L. R.; DE ALMEIDA ALVES, A. A. A coleta seletiva à luz da PNRS nos estados brasileiros: uma revisão sistemática integrativa. Revista Brasileira de Planejamento e Desenvolvimento, v. 7, n. 5, p. 646-669, 2018.

ORGANIZAÇÃO DAS NAÇÕES UNIDAS. Transformando Nosso Mundo: A Agenda 2030 para o Desenvolvimento Sustentável. Brasil, 2015. Disponível em: https://nacoesunidas.org/pos2015/ agenda2030/. Acesso em: 2 set. 2019.

SANTOS, G. O; RIGOTTO, R. M. Possíveis impactos sobre o ambiente e a saúde humana decorrentes dos lixões inativos de Fortaleza (CE). Revista Saúde e Ambiente, v. 9, n. 2, p. 45-58, 2008.

SENADO FEDERAL (Brasil). Rumo a 4 bilhões de toneladas por ano: É a previsão da ONU para o ano de 2050, no atual ritmo de crescimento. Brasil: Em Discussão, 2014. Disponível em: http:// www.senado.gov.br/noticias/jornal/emdiscussao/ residuos-solidos/materia.html?materia=rumo-a-4bilhoes-de-toneladas-por-ano.html. Acesso em: 4 set. 2019 .

VERDÉLIO, A. Governo federal defende prorrogação do prazo da lei que acaba com os lixões. Agência Brasil, Brasília, 27 fev. 2016. Disponível em: http:// agenciabrasil.ebc.com.br/geral/noticia/2016-02/ governo-federal-espera-pela-prorrogacao-doprazo-da-lei-que-acaba-com-os. Acesso em: 2 set. 2019. 